\title{
Dossiê
}

\section{Luta hegemônica e populismo na América Latina: teoria e práxis a partir de Ernesto Laclau}

\author{
Hegemonic struggle and populism in Latin America: \\ theory and praxis beyond Ernesto Laclau
}

\author{
Mayra Goulart \\ Professora, Universidade Federal Rural do Rio de Janeiro (UFRRJ), \\ Seropédica, RJ, Brasil \\ mayragoulart@gmail.com
}

\begin{abstract}
Resumo: O objeto deste artigo é o conceito laclauniano de populismo, cuja análise será realizada mediante uma genealogia histórico-política das mobilizações do conceito na América Latina. Após esse primeiro movimento, que visa situar a obra de Ernesto Laclau como um ponto de inflexão na teoria e na práxis até então associada à categoria, serão desenvolvidos dois desdobramentos axiológicos desse movimento. O primeiro, diz respeito a sua relação com o marco conceitual estabelecido em Hegemonia e Estratégia Socialista (1985). O segundo assume uma feição crítica, uma vez que almeja apontar e ultrapassar as debilidades da conceitualização do autor. Para isso, serão apresentadas outras ferramentas analíticas que permitam responder à seguinte pergunta: Como diferenciar os movimentos populistas, em termos de manutenção e performance no governo? Diante desta questão, espero realizar uma contribuição para o debate em torno do conceito de populismo, expandindo sua função heurística e tornando-o apto à análise de governos e políticas públicas, mediante a incorporação de um critério normativo associado à ideia de luta hegemônica e a dinâmicas de empoderamento econômico e político do demos.
\end{abstract}

Palavras-chave: Populismo; América Latina; Hegemonia; Teoria política; Democracia; Liberalismo.

\footnotetext{
Abstract: The object of this article is the Laclaunian concept of populism. This analysis will be performed by a genealogy, which seeks to address the manifestations of this category in Latin America correlating theory and praxis. After this first movement, that situates Laclau's work as a point of inflection in the theory and praxis previously associated with this category,
} 
I will present two axiological developments. The first concerns the relationship between the concept of populism and the theoretical framework established in Hegemony and Socialist Strategy - Towards a Radical Democratic Politics (1985). The second takes on a critical aspect, since it aims to point and overcome some limitations in Laclau's concept. For this, other analytical tools will be considered in order to answer the following question: How to differentiate populist movements in terms of maintenance and performance in government? By dealing with this question, I hope to make a contribution to the debate around this category, expanding its heuristic function and making it fit for the analysis of governments and public policies. This will be done through the incorporation of a normative criterion associated with the idea of hegemonic struggle and with the economic and political empowerment of the demos.

Keywords: Populism; Latin America; Hegemony; Political theory; Democracy; Liberalism.

\section{Introdução}

O objeto deste artigo é o conceito laclauniano de populismo. Sua análise, por sua vez, será realizada a partir da hipótese de que a obra de Ernesto Laclau demarca uma viragem na teoria e na práxis até então associada à categoria, despojando-o de sua significação particularmente negativa. Após fundamentar este argumento mediante uma breve genealogia do conceito, buscar-se-á apontar dois desdobramentos axiológicos desse movimento.

O primeiro, a ser desenvolvido na segunda seção deste trabalho, diz respeito a sua relação com o marco conceitual estabelecido em Hegemonia e Estratégia Socialista (LACLAU; MOUFFE, 1985), que, embora escrito vinte anos antes da publicação de A Razão Populista (LACLAU, 2005), nos oferece um instrumental teórico interessante para a compreensão dos objetivos políticos do autor. Tais propósitos, como será demonstrado, resultam na confecção de uma categoria capaz de enquadrar, em uma moldura positiva, as novas lideranças que ascendiam eleitoralmente na América Latina do início do século XXI. Com isso, Laclau utiliza sua própria reflexão como uma ferramenta da luta hegemônica travada na região, conciliando em um mesmo movimento teoria e práxis.

O segundo desdobramento, a ser desenvolvido na terceira parte do artigo, assume uma função crítica, uma vez que almeja apontar e ultrapassar as debilidades da conceitualização do autor. A teoria laclauniana tem um forte potencial descritivo, principalmente no que diz respeito ao processo estabelecido entre o surgimento de 
novas lideranças e sua chegada ao poder, sendo o conceito particularmente útil para analisar fenômenos discursivos?

No entanto, como será argumentado na terceira etapa do trabalho, sua teoria não atinge o mesmo potencial descritivo no que diz respeito ao período posterior à chegada dos líderes populistas ao poder, além de não oferecer elementos normativos capazes de avaliar sua performance no governo. Sendo assim, a partir da observação destas fragilidades, este paper visa propor alternativas para contornar algumas debilidades inerentes ao conceito laclauniano de populismo. Para isso, serão apresentadas outras ferramentas analíticas que permitam responder a seguinte pergunta: Como diferenciar os movimentos populistas, em termos de manutenção e performance no governo?

Para contemplar tais lacunas, utilizar-se-á a crítica apresentada por Nadia Urbinati (2014) em Disfigured Democracy. Nesta obra, a autora oferece instrumentos heurísticos profícuos para ampliar a abrangência analítica do conceito de populismo, embora o mesmo não possa ser dito de seus fundamentos normativos, que resvalam em uma concepção demasiado abstrata e idealizada da democracia liberal, particularmente incompatível com o contexto latino-americano. Diante desta conclusão, buscar-se-á um critério normativo mais adequado a esta realidade. Deste modo, espero realizar uma contribuição para o debate em torno do conceito de populismo, expandindo sua função heurística e tornando-o apto à análise de governos e políticas públicas. Conforme delineado na conclusão, este critério será encontrado na ideia de luta hegemônica e fará referência a dinâmicas de empoderamento econômico e político do demos.

\section{Populismo na América Latina}

Polissêmico, polêmico e cliché, o conceito de populismo pode ser usado como um marcador das viragens pelas quais passou o pensamento e a práxis política latino-americana. Essa função de bússola, capaz de conduzir o observador interessado em caminhar pelos labirínticos caminhos da história política deste subcontinente, resulta da sensibilidade do conceito às mudanças de humores na região, mas, também, da reincidência de alguns

\footnotetext{
1 Essa ressalva não ignora o caráter material dos fenômenos discursivos e se alinha a um horizonte conceitual onde essências e nomes, linguagem e atos não suportam nenhuma diferenciação subjetiva. Sob essa perspectiva, na qual se insere também a obra de Laclau (e Mouffe), "[...] elementos linguísticos e não linguísticos não são meramente justapostos, mas constituem um sistema estruturado e diferenciado de posições, isto é, um discurso" (LACLAU; MOUFFE, 1985, p. 108 - tradução nossa).
} 
de seus temas como o personalismo, o multiclassismo e a debilidade das instituições liberais. Em particular, tal reincidência está associada a de uma estrutura na qual a sociedade civil tem pouco espaço para o exercício da autonomia, haja vista a excessiva concentração de recursos econômicos e, por conseguinte, poder político, nas mãos de lideranças locais, carentes de projetos nacionais ulteriores à manutenção de seu poderio.

Diante disto, elites políticas que almejem a execução de uma agenda programática em âmbito nacional dependem da capacidade de arregimentação destes dois elementos, cujos interesses na maioria das vezes são antagônicos. Ao longo da história, todavia, a combinação entre ambos muitas vezes se deu em termos inversamente proporcionais, isto é, quanto mais apoio das elites, menor a necessidade de disputar o apoio do povo, e vice-versa. Desta maneira, quando enveredam pela segunda opção, buscando sustentação política na popularidade entre os cidadãos comuns, em detrimento das elites tradicionais, os atores políticos são tipificados como populistas. Tal opção, remete à pressuposição de que o Estado deve ser utilizado como instrumento redistributivo que visa o favorecimento da cidadania (do povo) em detrimento de grupos privilegiados (oligarquias).

Não obstante, se observarmos uma das origens axiológicas do conceito neste subcontinente, percebe-se que o termo foi utilizado como uma espécie negativo sobre o qual marxistas e liberais² revelavam suas impressões sobre os governos nacionalistas. Estimulados pelas oportunidades criadas em tempos de guerra, este tipo de nacional-desenvolvimentismo se dissemina na América Latina, assumindo várias facetas, a exemplo do argentino Juan Domingo Perón (1946-1955 e 1973-1974); do chileno Carlos Ibáñez del Campo (1927-1931 e 1952- 1958); do brasileiro Getúlio Vargas (1930-1945 e 1951-1954) do mexicano Lázaro Cárdenas (1934-1940); do peruano, Fernando Bealúnde Terry (1963-1968 e 1980-1985); e do equatoriano José María Velasco Ibarra (1934-1935, 1944-1947, 1952-1956, 1960-1961 e 1968-1972)3.

Neste negativo, o retrato deste período passa a ser revelado pelas suas ausências. No caso dos marxistas, é ressaltado o caráter multiclassista desses movimentos, denunciado como falta de consciência de classe. No caso dos liberais, por sua vez, a denúncia gira em torno da ausência de uma sociedade civil autônoma e empreendedora.

2 Dentre as inúmeras referências possíveis destaco como exemplo da crítica marxista ao populismo as contribuições de Weffort (1968) e Cardoso e Faletto (1969). Entre os liberais, por sua vez, destaco O'Donnell (1972) e Pereira (1985, 1991a).

3 Para uma historiografia mais completa sugiro: lanni (1975) e Vilas (1994). 
Sendo assim, até o início do século XXI, o populismo disseminou-se no vocabulário político latino-americano como uma categoria negativa utilizada para denunciar governos que manipulavam os trabalhadores e cooptavam os atores econômicos, bloqueando a compreensão de seus interesses e a realização de seus verdadeiros propósitos. Em última instância, marxistas e liberais uniam-se em um entendimento do Estado e de seus operadores como obstáculos à livre ação daqueles que seriam os responsáveis pelo progresso.

As interpretações que de algum modo atribuem ou observam no Estado o papel de operador da transição entre esta disposição tradicional e as sociedades industriais modernas, não se apresentam como um meio termo, ou como uma terceira via entre as duas correntes acima apresentadas, mas, sim, como uma perspectiva essencialmente distinta. É o caso da leitura reformista, apresentada por autores como Gino Germani, Octavio Ianni e Torcuato Di Tella (GERMANI; IANNI; DI TELLA, 1973) que observam nas alianças de classes, articuladas pelos discursos populistas, uma estratégia intermédia entre o fascismo e a revolução burguesa.

Com isso, estes líderes teriam sido capazes de ultrapassar os limites determinados pela mentalidade latifundiária e agroexportadora das oligarquias tradicionais, logrando, em maior ou menor escala, o fortalecimento do mercado interno e a promoção de uma política comercial e cambial protecionista, voltada ao estímulo da industrialização através da substituição de importações (SACHS, 1989; DORNBUSCH; EDWARDS, 1991)

Não obstante, ainda que se aproximem em termos econômicos e que se distanciem das leituras marxistas e liberais, esta sociologia da modernização assume diferentes posicionamentos face aos desdobramentos políticos dos regimes nacionalistas em questão, que são identificados ora como decididamente autoritários, como na interpretação de Germani, ora como considerava Di Tella, enquanto a democracia possível naquelas circunstâncias (MITRE, 2009, p. 10-17).

Avançando no tempo, observa-se que, nas décadas de 1980 e 1990, a controvérsia acerca dos desdobramentos políticos do populismo perde espaço para um conjunto de considerações que dissertam sobre seus efeitos econômicos, caracterizados como herança maldita legada pelos governos nacional-desenvolvimentistas (DORNBUSCH; EDWARDS, 1991; KAUFMAN; STALLINGS, 1991; FAUCHER, DUCATENZEILER; REA, 1993). Expressão da hegemonia do ideário neoliberal, entendido como Consenso de Washington, essas 
abordagens criticam exatamente aquilo que foi considerado como principal legado do populismo: as estratégias modernizadoras nacional desenvolvimentistas. Sob tal perspectiva, estas opções teriam resultado apenas em uma industrialização precária, no endividamento do Estado e na criação de uma burguesia parasitária.

O populismo econômico passa a ser, então, uma expressão utilizada para tipificar políticas monetárias e fiscais de natureza expansiva, sustentadas pela disponibilidade conjuntural de reservas internacionais e pela supervalorização cambial. O resultado destas políticas, no curto prazo, estaria associado a uma hiperbólica elevação da inflação e, no longo, à crise da dívida (SMITH, 1990, 1991). Ademais, na tentativa de amenizar o processo inflacionário, por vezes esses governos recorreram ao subsídio das importações, acentuando a dinâmica de endividamento e fuga de capitais (WEYLAND, 2001).

A crise da dívida - que se deflagra em diferentes países latino-americanos durante as décadas de 1980 e 1990 - é, pois, o resultado de um ciclo vicioso entre as desvalorizações da moeda, a redução do poder de consumo do trabalhador, da arrecadação por parte do governo e dos investimentos, por um lado, e, por outro, da redução da produção econômica e da elevação do desemprego (PEREIRA, 1991b).

Diante da iminência de um colapso de seus sistemas econômicos, formou-se um consenso entre parte das elites nacionais, credores e atores internacionais em torno da implementação de medidas de estabilização baseadas na contenção do gasto fiscal e no congelamento dos salários. Neste contexto, surge no horizonte político latino-americano, um conjunto de líderes comprometidos, de modo mais, ou menos explícito, com essa agenda desenvolvida através de programas de reajuste executados com a assistência do Fundo Monetário Internacional. Os principais exemplos do período são Carlos Menem, na Argentina (1989-1999), Fernando Collor de Mello, no Brasil (1990-1992) e Alberto Fujimori, no Peru (1990-2000).

No entanto, observando sua trajetória política é possível perceber que, embora críticos do nacional-desenvolvimentismo, estes personagens reúnem uma série de atributos políticos que os aproximam do populismo clássico, como o personalismo, a crítica às instâncias de representação tradicional e a concentração de poderes no Executivo. Em comum com o populismo no passado, esses novos líderes apresentam uma retórica voltada ao cidadão comum, em oposição às elites. Esta categoria, todavia é ressignificada para abarcar outros atores, em particular aqueles que representavam a 
base de sustentação do populismo nacional desenvolvimentista, isto é, os trabalhadores formais e a burguesia nacional, organizados, respectivamente em sindicatos e entidades patronais (SCHNEIDER, 1991; STEIN, 1980).

Em sua fase neoliberal os discursos populistas se dirigem a uma base social ampliada pelas reformas ortodoxas: desempregados, trabalhadores informais, excluídos, oprimidos e pobres de maneira geral. Em seus atos de fala, todavia, estes sujeitos são apresentados em uma relação de antagonismo que ignora o impacto do neoliberalismo, enfatizando os privilégios concedidos pelo nacional desenvolvimentismo às elites a ele associadas. Não obstante, em virtude de sua abrangência, estas categorias encontram aderência em um panorama marcado por profundas alterações no mercado de trabalho, além de serem capazes de agregar uma multidão indivíduos que passaram a uma situação de pobreza e desemprego, cujas esperanças são depositadas na recuperação econômica a ser alcançada através dos ajustes (WEYLAND, 1996).

É da frustração dessas expectativas que surge a mais recente viragem no conceito de populismo, propiciada pela insatisfação com os resultados alcançados através da agenda neoliberal e com os líderes com ela comprometidos (VILAS, 2004). Este sentimento, se traduz, no despontar do século XXI, em uma conjuntura de grave crise econômica e política, que culmina com a vitória eleitoral de atores que representavam uma mudança de rumos ${ }^{4}$. É nesse contexto que surge o objeto deste trabalho: o conceito laclauniano de populismo.

\section{Luta hegemônica e populismo no século XXI: teoria e práxis de Ernesto Laclau}

Compartilhada por parcelas da classe média e pelas classes populares, particularmente atingidas pelas consequências deletérias das investidas neoliberais, a rejeição aos discursos de austeridade manifestou-se em diferentes graus. Em alguns países como Venezuela, Bolívia e Equador, ela assumiu um espectro de singular radicalidade (LA TORRE, 2013),

4 Em 2000, dois anos após a vitória de Hugo Chávez na Venezuela, Ricardo Lagos do Partido Socialista do Chile, foi eleito. Em 2002, foi a vez de Lula, seguido por Néstor Kirchner que se elege presidente da Argentina, em 2003. Um ano depois, Tabaré Vázquez, da Frente Ampla, vence no Uruguai. Em 2005, foi a vez de Evo Morales, do Movimento ao Socialismo. No ano seguinte, o equatoriano Rafael Correa do Pátria Altiva e Soberana, consagrou-se presidente, também derrotando lideranças políticas tradicionais. Por fim, em 2008, no Paraguai, Fernando Lugo, obtém uma inédita vitória sobre o Partido Colorado, no poder por mais de 60 anos. 
em outros, todavia, tal insatisfação não adquiriu feições análogas, sendo a ideia de mudança amainada por compromissos com as elites tradicionais, em especial aquelas identificadas com o capital financeiro (PEREIRA DA SILVA, 2015; GÓMEZ LEYTON; MOREIRA; RAUS, 2008). Nesses casos, notadamente Brasil e Chile, a reversão de algumas políticas de austeridade e a adoção de programas de transferência de renda foram o resultado de dinâmicas de barganha instauradas no plano da sociedade civil e em suas instâncias de representação (LANZARO, 2007).

Inserindo-se na lógica descrita na seção anterior, quanto maior o afastamento em relação aos interesses das elites, maior a dependência do apoio popular e, por conseguinte, mais fortemente esses líderes são identificados com o conceito de populismo. No entanto, ainda que tenha mantido seus principais elementos - como a base popular, o personalismo e a concentração de poderes do Executivo - é neste contexto que a categoria sofre a sua transformação mais radical, operada pela reformulação realizada por Ernesto Laclau, em A Razão Populista (RP).

Conforme desejamos argumentar através dessa breve historiografia acerca das viragens do conceito na América Latina, pela primeira vez, o conceito perde sua feição pejorativa, assumindo uma perspectiva que se apresenta como descritiva, embora assuma uma função criptonormativa. Essa segunda característica está associada aos propósitos políticos do autor, no contexto da luta hegemônica, travada na região por uma nova elite política, que chega ao poder no século XXI. Com esse objetivo, a categoria foi redefinida com o propósito de tipificar estes novos atores, destacando seus principais elementos comuns: a recuperação de um ideal nacional-desenvolvimentista, discursivamente construído pela rejeição da agenda neoliberal, e, sobretudo, pela polarização da sociedade entre oprimidos e opressores.

No entanto, ainda que seja possível detectar no populismo do passado a configuração de fronteiras de antagonismo, em sua nova fase elas se distinguem por uma dimensão identitária, que se revela na intenção de reconhecer atores que se mantiveram em uma posição de invisibilidade e subalternidade ao longo da história. Nessa nova acepção, o líder populista não guia ou lidera o povo, ele o representa por que faz parte dele, uma vez que compartilha sua identidade (ARDITI, 2005, p. 98-100).

Conforme o argumento aqui elaborado, o conceito gramsciano de hegemonia, recuperado em Hegemonia e Estratégia Socialista (HES), pode ser indicativo do propósito 
de Laclau de reformular o conceito de populismo, despojando-o de suas feições negativas, de forma a permitir que ele atue como um instrumento na luta política travada pelas lideranças nele tipificadas. Sendo assim, é possível imaginar uma conexão entre as duas obras, buscando na primeira (HES) a chave para a compreensão da segunda (RP), de modo a lançar luz sobre os motivos que levam o autor a reformular o conceito de populismo, drenando-o de sua negatividade.

A ideia de hegemonia desponta na tradição marxista, demarcando uma inflexão no debate teórico acerca da relação entre estrutura econômica e superestrutura política, enfatizando a importância da última na configuração da teia de relações sociais que forma as diferentes comunidades distribuídas no tempo e no espaço. Com isso, a sociedade civil e a ideologia emergem, respectivamente, como espaço e ferramenta das lutas por poder. No entanto, embora tenha sido primeiramente formulada por Vladimir Lênin, é com Antonio Gramsci que a noção de hegemonia assume um papel central no interior do marxismo. As formulações dos dois autores seguem uma relação de continuidade, porém estão endereçadas a contextos históricos distintos.

Lênin se dirige, pois, a uma conjuntura política singular, marcada por convulsões sociais (a Revolução de Fevereiro, de 1917, que por sua vez, sucedeu a Revolução Russa de 1905) caracterizadas por dificuldades de organização por parte das forças políticas envolvidas, e pelo engajamento de um grande número de cidadãos militarizados (sobretudo após o envolvimento da Rússia na Primeira Guerra Mundial). Diante desse panorama, o autor compõe uma ode ao partido como estrutura de organização da ação coletiva, voltada à conquista do aparato estatal através das armas (COX, 2007).

Gramsci, todavia, se endereça a um país cujas instituições do Estado e os partidos políticos encontram um grau de consolidação maior, enquanto a população comum se mantém relativamente pouco mobilizada, quando comparada ao caso russo. Nesse contexto, são os intelectuais que ganham destaque como instrumentos de irradiação ideológica em uma disputa por corações e mentes, cujo locus prioritário é a sociedade civil (ALVES, 2010, p. 85).

Saltando uma série de debates e reformulações do conceito, este texto se aterá à apropriação realizada por Chantal Mouffe e Ernesto Laclau. Dirigindo-se ao panorama histórico e intelectual distinto marcado, no campo político, pelo fracasso do socialismo realmente existente e, no âmbito teórico, pela crítica ao pressupostos racionais e 
normativos que o estruturavam, os autores operam uma significativa engenharia conceitual. Nessa abordagem, estruturada a partir da ideia de antagonismo originalmente presente na noção de luta hegemônica, os sujeitos são apresentados sem qualquer alusão a conteúdos, identidades ou essências transcendentes, sendo compreendidos, portanto, como o produto de um contexto histórico e linguístico particular, efêmero e instável por definição.

Em A Razão Populista, Laclau deixa claro que a agregação das demandas em uma cadeia de equivalência pressupõe uma assimetria essencial entre a comunidade como um todo e suas partes constitutivas, sendo que esta unidade depende de um processo de catacrese, no qual uma das partes se identifica com o todo (LACLAU, 2005, p. 24). A lógica desta operação é o que o autor denomina de razão populista (SILVA, 2016, p. 266).

Esta abordagem remete às formulações apresentadas em Hegemonia e Estratégia Socialista (HES), publicada em 1985, em parceria com Chantal Mouffe. No livro, observa-se a configuração de um horizonte pós fundacionalista que implode as bases da filosofia do sujeito que alicerçava a ideia de um sujeito universal. Neste contexto, a luta contra-hegemônica, delineada pelos autores como um projeto de democracia radical, depende de uma articulação artificial e contingente entre os diferentes sujeitos coletivos, cada qual portador de uma demanda não atendida pela ordem atual (SILVA, 2013, p. 106).

Esse papel pode ser desempenhado pelo líder populista, conforme uma perspectiva na qual o critério normativo que julgará sua performance deriva desta função contra-hegemônica. O propósito deste artigo é contribuir para que este parâmetro seja incorporado ao conceito de populismo, tornando-o uma ferramenta heurística útil para a análise de fenômenos políticos que reivindiquem tal papel.

Nas palavras dos autores em uma passagem na qual abordam o problema da articulação de sujeitos políticos contra-hegemônicos em um contexto marcado pela pluralidade de demandas e identidades sociais:

Um de seus princípios centrais é a necessidade de criar uma cadeia de equivalência entre as várias lutas democráticas contra diferentes formas de subordinação. Argumentamos que as lutas contra o sexismo, o racismo, a discriminação sexual e a defesa do meio ambiente precisam ser articuladas com as dos trabalhadores em um novo projeto hegemônico de esquerda. Para colocá-lo na terminologia que recentemente se 
tornou moda, insistimos que a esquerda precisa abordar questões de "redistribuição"e "reconhecimento". Isso é o que entendemos por "democracia radical e plural" (LACLAU; MOUFFE, 1985, p. XVII - tradução nossa).

Observando nas lideranças surgidas ao final do século XX uma alternativa para a formação de um sujeito político contra-hegemônico, Laclau faz uma opção arriscada. Em vez de centrar sua abordagem nas "ausências", como fizeram marxistas e liberais no passado, denunciando no populismo a falta de consciência de classe ou o afastamento dos cânones da democracia liberal, o autor dedica-se às suas qualidades, que dizem respeito ao caráter inclusivo destes governos, à implementação de uma agenda econômica distributiva e a uma maior abertura à participação popular.

Neste esforço, Laclau, dirige-se àqueles que observam nestas lideranças uma ameaça de recrudescimento autoritário, atentando para o aporte de legitimidade conferido pelo amplo apoio da maioria da população. Com isso, seria possível obter avanços democráticos (em particular em sua dinâmica material), em um contexto de debilidade das instituições liberais. Este é o principal legado do populismo na região, no que diz respeito a um conjunto de políticas adotadas em favor das classes populares, nas quais o Estado reivindicou de modo mais explícito suas funções redistributivas. Por isso, esta categoria esteve originalmente associada a governos nacionalistas ou nacional-desenvolvimentistas, que, malgrado suas idiossincrasias, se aproximam no compromisso com o aumento das capacidades estatais e com projetos de crescimento econômico e distribuição de renda.

Contudo, para conferir o devido reconhecimento a este legado, é preciso ir além da teoria laclauniana, limitada à dimensão discursiva, procurando critérios úteis para analisar as performances dessas lideranças no poder. É nessa busca que nos deteremos sobre a crítica apresentada por Nadia Urbinati.

\section{O risco populista e a democracia desfigurada}

Ao assumir o pós-fundacionalismo para definir o horizonte epistemológico marcado pela superação da filosofia do sujeito, Laclau e Mouffe pressupõem a possibilidade de retomar o ideal moderno de autoafirmação (self-assertion) separando-o da noção de auto-fundação, na medida em que a crença na capacidade da razão humana de encontrar 
fundamentos últimos para a existência é incompatível com a rejeição de suas bases metafísicas, essencialistas e universalizantes (SILVA, 2013, p. 80-99).

Nesse esforço, é formulada uma teoria acerca da formação dos sujeitos políticos despojada de qualquer essencialismo, na qual toda identidade se configura sob uma perspectiva relacional, isto é, através de uma relação de antagonismo. Sob esta perspectiva, a identidade de um sujeito não the é intrínseca, mas depende da relação que ele estabelece com outros termos num sistema de diferenças historicamente construído e instável, uma vez que, composto por estruturas discursivas (e sujeitos) antagônicas que impedem seu completo fechamento em uma só totalidade (LACLAU, 1994, p. 1-7; ALVES, 2010, p. 89).

O conceito de hegemonia é, então, recuperado pelos autores, adquirindo feições de atributo inerente à formação e transformação das comunidades políticas, posto que considerado como solução precária e provisória para uma crise na qual uma parte, que até então supunha preencher o vazio da totalidade, deixa de ser capaz de fazê-lo, sendo substituída por outra, conforme explicitado em HES:

O conceito de hegemonia não emerge para definir um tipo novo de relação em sua identidade específica, mas para preencher um hiato aberto na cadeia da necessidade histórica. Hegemonia irá aludir a uma totalidade ausente e às diversas tentativas de recompô-la e rearticulá-la que, ao superar esta ausência originária, torna possível conferir às lutas um sentido e às forças históricas serem dotadas de plena positividade. Os contextos nos quais o conceito aparece serão aqueles de uma falha (no sentido geológico) de uma fissura que precisa ser preenchida, de uma contingência que precisa ser superada. Hegemonia não será o desdobramento majestoso de uma identidade, mas a resposta para uma crise (LACLAU; MOUFFE, 1985, p. 7 - tradução nossa).

Porém o pós-fundamentalismo, enquanto epistemologia impermeável a princípios transcendentes, traz consigo alguns inconvenientes. Pois, se o ato de representação constitui simultaneamente representantes e representados, não havendo uma essência coletiva ou vontade geral que o transcenda, torna-se mais difícil subordiná-lo a qualquer ideia de responsabilidade alheia aos seus ditames, visto que não fica claro a quais vontades ou interesses os representantes devem ser responsivos e que tipo de controle o demos deve exercer sobre eles. Ou, em outros termos, diferentemente das noções de razão e emancipação, que servem como horizonte normativo da luta hegemônica gramsciana, 
a razão populista não opera a partir de critérios valorativos de legitimidade para além do ato de representação particular entre os líderes e seus seguidores. Diante disto, agrava-se o risco de que, por pressupor uma identidade substantiva com o demos, o Cesar dele se desvincule, agindo em seu nome como bem entender (RODRIGUES; SILVA, 2015).

Em contraste com entendimento liberal sobre o processo de representação, que sublinha a pluralidade de opiniões e a proteção das minorias, a formulação laclauniana tende a realçar a homogeneidade e as maiorias. Diante disto, destacam-se dois problemas centrais: (1) o que fazer com as parcelas da população que não partilham da mesma identidade dos grupos majoritários ?; (2) quais os limites dessa identificação majoritária, tendo em vista o caráter multifacetado dos indivíduos e grupos sociais?

Na tensão entre a regra da maioria - enquanto princípio que alimenta as pretensões de legitimidade democrática - e o pluralismo - como elemento inerente a qualquer processo decisório em sociedades modernas - reside o principal obstáculo à sobrevida do ideal democrático em um contexto tão diferente daquele que o originou. Diante desta aporia, é preciso observar o esforço de Laclau em afirmar que, sob uma perspectiva normativa, a aclamação da maioria não é suficiente para conceder legitimidade a um ordenamento politico. Este ponto é central para a argumentação aqui empreendida, na medida em que evita uma associação precipitada entre populismo e cesarismo.

A crítica à esta formulação, todavia, não pode omitir que Laclau alerta seus leitores sobre os riscos inerentes a este tipo de vínculo, chamando atenção para o caráter ambíguo da razão populista, enquanto lógica que pode estar a serviço de movimentos progressistas e reacionários. Em suas palavras:

Um regime não pode ser simplesmente populista. Tem que ser ao mesmo tempo outras coisas [...] ou seja, o populismo não define a ideologia de um movimento, o que define é uma forma de construção do político que procede através da divisão dicotômica da sociedade em dois campos. Diante disso, pode-se ter, por um lado, o institucionalismo, que seria o oposto, quer dizer, demandas que não se agrupam através de polos matriciais, mas tendem a desenvolver-se separadamente umas das outras e, de outro lado, a outra posição extrema seria a posição populista, quer dizer, um discurso que divide a sociedade em dois campos, os de cima e os de baixo [...] Agora, eu creio que todo regime viável tem que combinar de alguma maneira, em distintas proporções o institucionalismo e o populismo (LACLAU, 2010). 
Considerando esta ressalva acerca da importância das instituições democrático-liberais como contrapeso às tendências cesaristas do populismo, o objetivo aqui será averiguar a hipótese de que, mesmo não sendo imperativas, elas podem indicar um risco inerente a esta forma de representação. Em outras palavras, buscar-se-á averiguar se, embora a associação entre populismo e cesarismo não seja necessária no que diz respeito aos elementos que configuram a gênese dos movimentos, esta associação pode ser pertinente quando voltada à análise da performance destas lideranças no poder. Nesta medida, como será demonstrado a seguir, extrapolando a conceitualização laclauniana, governos populistas estariam mais propensos a contornar obstáculos ao exercício de seu poder, através do estabelecimento de mecanismos que reduzam o poder de veto dos atores e instituições vigentes. A razão populista, alerta Nadia Urbinati, tem as suas consequências institucionais. A questão é saber se, sob um ponto de vista normativo, elas são necessariamente negativas.

Posicionando-se de maneira afirmativa diante desta questão, em Democracy Disfigured, Urbinati (2014) dedica-se a alguns fenômenos contemporâneos que desvirtuam ou, na terminologia do texto, desfiguram os sistemas políticos inseridos em um horizonte de expectativas que visa conciliar democracia e liberalismo. Dentre eles está o populismo.

Segundo a hipótese apresentada no livro, um dos elementos que fazem parte de sua essência seria a hostilidade ao liberalismo e aos princípios da democracia constitucional (divisão de poderes, direitos das minorias e etc.). O que pressupõe, uma vez no poder, o ímpeto de realizar alterações institucionais com o propósito de aumentar a centralização dos poderes nas mãos do líder e de seus seguidores.

Afastando-se da tradição da filosofia política, que trata de questões de legitimidade a partir de uma analogia com o que seria a "substância" do corpo político, Nadia Urbinati utiliza a ideia de figura. Entendido como fenótipo, o conceito remete a um conjunto de atributos que permite a um observador externo reconhecer um determinado regime, distinguindo-o de outros. Ao falar da desfiguração da democracia, a autora almeja detectar modos de esgarçamento das instituições liberais que, mesmo não alterando nominalmente a forma de governo, podem ser externamente observáveis.

É o caso da relação entre populismo e democracia liberal, definida como uma diarquia, isto é, como sistema dual no qual a "vontade" (procedimentos decisórios) e a "opinião" (interesses e desejos que se estabelecem fora do plano institucional) se influenciam 
mutuamente (URBINATI, 2014, p. 14). Essa dinâmica entre vontade e opinião demanda, por sua vez, um arcabouço institucional caracterizado pelo respeito às liberdades individuais, pela divisão, equilíbrio e controle recíproco de poderes (checks and balances) e pela natureza representativa de seu processo decisório, que inclui a preocupação com a representação de interesses e sujeitos sociais minoritários (pluralismo).

O populismo, por um lado, surgiria como uma forma de preencher o vazio inerente às concepções procedimentais da democracia (URBINATI, 2014, p. 143), que a esvaziam de sua substância ética. Em contrapartida, esse preenchimento se dá mediante uma narrativa simbólica que compromete a competência das instituições de atuarem como médium capaz de relacionar e separar os interesses sociais e o Estado, que tornar-se-ia, então, uma expressão direta da "opinião". Ao identificar o político com o social - as decisões do líder, ou de seus correligionários no Parlamento, com a opinião pública - o populismo mitiga o caráter dual que caracteriza a democracia representativa.

Por este motivo, para a autora, ele seria um dos fenômenos responsáveis pela sua desfiguração, reduzindo o dualismo entre vontade e opinião através de uma simplificação do campo social, operada pela polarização. Isto porque, ao configurar um populus, através de uma relação de antagonismo, o resultado seria uma visão unitária de povo, que comprime a pluralidade de identidades e sujeitos que compõem o tecido social.

Diferentemente de Laclau, Urbinati atribui um caráter necessário à deriva plebiscitária que acompanharia este tipo de discurso, cujo inimigo subjacente seria o próprio sistema representativo, no que diz respeito ao pluralismo e ao respeito às minorias. Por conseguinte, um dos elementos que fazem parte da razão populista seria a hostilidade ao liberalismo e aos princípios da "democracia constitucional" (divisão de poderes e direitos das minorias, etc.). Sua operação, todavia, não se limita a gênese dos movimentos, mediante à configuração de vínculos de identidade entre os líderes e seus seguidores. É neste ponto que as considerações de Urbinati se tornam particularmente úteis para o propósito deste artigo.

Se a razão populista continua operando após a ascensão eleitoral dessas lideranças e, por conseguinte, para além do plano discursivo, isso significaria uma práxis política voltada a contornar os obstáculos à implementação da vontade da maioria, representada na figura do líder. Por este motivo, uma vez no poder, o populismo estaria associado à alteração das formas institucionais características da democracia constitucional. Dentre estas 
alterações estaria, o aumento das competências do Executivo, o favorecimento de dinâmicas majoritárias no Parlamento e a aprovação de mecanismos de democracia direta (MDDs) como os plebiscitos e referendos.

Sobre os últimos, entretanto, a despeito da pertinência e da sofisticação da argumentação da autora, é preciso ressaltar a ausência de conexões causais entre MDDs e concentração de poder. A este respeito, Urbinati apenas afirma que, mesmo quando incorpora elementos de democracia direta, estes envolveriam apenas a participação difusa por parte dos cidadãos, pois, mediante o populismo esses instrumentos se transformam em métodos de concentração de poder (URBINATI, 2014, p. 142). Como no cesarismo plebiscitário, eles serviriam apenas para a aclamação do líder. Este ponto, ao meu ver, é útil para explicitar as limitações inerentes ao seu argumento.

O viés majoritário dos MDDs é inequívoco, assim como sua afinidade com performances discursivas que reforcem uma concepção unitária de povo, como é o caso das cadeias de equivalência que configuram a razão populista. Não obstante, é preciso indagar se estes devem ser compreendidos como uma ameaça ou uma opção válida diante de cenários em que a maioria da população tem suas demandas essenciais não atendidas pelas instituições liberais. Nestas circunstâncias, o viés majoritário, ou na terminologia de Urbinati a formação de uma maioria intensa (more intense majority), pode ser uma estratégia para lidar com tais demandas.

A este respeito, é interessante observar a passagem abaixo, na qual a autora reforça a associação entre democracia liberal e moderação política, enquanto atributo associado à presença das classes médias, condenando discursos que explicitam os antagonismos sociais. Em suas palavras:

Para que o equilíbrio social (e político) exista, um meio termo social é necessário. No caso da democracia, este meio termo persiste enquanto os muito pobres são poucos e os ricos sentem que a sua riqueza é segura mesmo que sejam uma minoria [...] Deslocar o meio e radicalizar os pólos sociais: é isso que a demagogia explicita e explora, é isso que ocorre quando a regra da maioria alcança uma intensidade que é estranha à democracia constitucional. Para que? Por que uma maioria mais intensa é necessária? [...] Por que os pobres, que estão sempre na maioria numérica, precisam de um certo ponto de uma maioria mais intensa? Por que simplesmente a maioria dos votos não é suficiente? (URBINATI, 2014, p. 151-152 - tradução nossa).

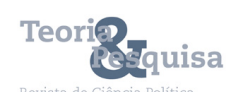


Sob esta perspectiva, uma vez que a regra da maioria e sua capacidade de transformar decisões majoritárias em política pública seria a norma das democracias, qualquer esforço no sentido de um empoderamento das maiorias, aumentando sua "intensidade" seria prejudicial. É nesse sentido pejorativo que o termo demagogia é apresentado como um dos elementos constitutivos do populismo (URBINATI, 2014, p. 150).

Diante desta colocação, em primeiro lugar, cabe refletir se esta norma é compatível com a natureza do sistema capitalista, no qual se observa a operação de minorias capazes de bloquear o atendimento das demandas majoritárias. Em seguida, considerando contextos em que as maiorias se encontram particularmente vulnerabilizadas, é interessante observar se tal intensidade não pode ser compreendida como uma resposta válida para a obtenção dos resultados alcançados.

A própria autora reconhece o papel das crises econômicas como variável conjuntural que contribui para a desfiguração da democracia. Segundo ela, "[...] polarização e parcialidade são características de uma maioria intensa criada pela demagogia"(URBINATI, 2014, p. 152 - tradução nossa). No entanto, nas passagens em que aborda a questão de forma mais direta, Urbinati recupera as contribuições de Aristóteles, que dificilmente pode ser considerado um democrata e certamente não se endereça a um contexto marcado por um sistema econômico caracterizado pelo princípio da acumulação.

É nesse descolamento com a realidade das sociedades contemporâneas que reside a limitação de seu argumento, que, embora nos ofereça ferramentas úteis para uma análise crítica da performance dos governos populistas, deixa de lado a importância de variáveis conjunturais e estruturais na consideração dos limites da própria democracia liberal.

Associar o êxito da democracia liberal à ausência de extremos econômicos apenas ressalta a inaplicabilidade deste regime como parâmetro normativo para análise de fenômenos políticos, sobretudo em contextos marcados pela desigualdade social e por crises econômicas. Em tais conjunturas, a classe média se encontra progressivamente comprimida pela concentração de renda que aumenta a polarização social, reduzindo o pluralismo de identidades alheias a ela. Nas palavras da autora:

Aristóteles oferece uma análise estrutural acerca das condições que preparam à insurgência da demagogia. A crise do pluralismo social e o estreitamento da classe média são os dois fatores intervenientes que acompanham esta transformação. A polarização 
entre ricos e pobres e a erosão da classe média são, ainda, hoje a origem da simplificação política (URBINATI, 2014, p. 150 - tradução nossa).

É a este contexto que os demagogos (ou populistas) se endereçam. Condená-los como elementos de desfiguração da democracia liberal é ignorar a hipótese de que eles sejam uma resposta plausível a uma degeneração que os precede. Apresentando um ponto de vista demofóbico, associado a uma concepção idealizada e abstrata de democracia, Urbinati denuncia a retórica majoritária e sua intensidade como instrumento de manipulação de elites, perante uma população passivamente cativa aos encantos do líder. Com isso, ela desconsidera a capacidade da plebe de tomar decisões que levem em conta seus interesses, observando-as como resultado de prestidigitação das lideranças. O populismo é, pois, novamente condenado sob um ponto de vista que, em última instância, contraria a própria ideia de democracia.

Em sua crítica a Laclau, Urbinati nos oferece instrumentos úteis que agregam capacidade analítica a sua conceitualização, estendendo sua potência analítica ao período pós eleitoral. Isto, contudo, vem acompanhado de uma perspectiva elitista e demasiado apartada da realidade material - especialmente quando temos em mente o contexto de países latino-americanos, assolados por graves problemas redistributivos. Ao utilizar como parâmetro normativo um conceito idealizado e abstrato de democracia, desconsidera-se a hipótese de que a aposta em uma liderança populista pode ser o produto de uma escolha válida de eleitores conscientes de seus riscos.

Para considerá-la, todavia, é preciso recorrer a um critério mais adequado a esta realidade, associado à resolução desses problemas mediante uma agenda de empoderamento político e material do demos. Este critério - como já havia insinuado Laclau ao inserir uma dimensão criptonormativa na razão populista - pode ser encontrado na ideia de hegemonia. O propósito desta crítica, por conseguinte, foi explicitar e reivindicar este elemento normativo contra-hegemônico enquanto parte constitutiva do conceito de populismo para, com isso, expandir sua potência heurística, tornando-o apto para analisar discursos, governos e políticas públicas. 


\section{Considerações finais}

O objetivo deste artigo foi analisar o conceito laclauniano de populismo, considerando alternativas que permitissem ultrapassar suas limitações. Com este propósito, na primeira seção, foi apresentada uma genealogia capaz de fornecer um enquadramento político-conceitual que explicita sua vinculação a um contexto específico, marcado pela ascensão de uma nova elite política na América Latina ao final do século XX. Em seguida, na segunda parte do artigo, argumentou-se que embora se pretenda descritiva a categoria apresenta elementos criptonormativos que ressaltam a legitimidade dos discursos proferidos por estes atores, caracterizados pelo empoderamento das classes populares em detrimento das elites.

No entanto, longe de criticar tal normatividade, este trabalho a ela se alinha. Ao enfatizar os limites analíticos da contribuição de Ernesto Laclau, meu propósito é incorporar à categoria elementos que ultrapassem o plano discursivo que caracteriza o surgimento dessas novas lideranças, mediante a configuração de vínculos de identidade com seus futuros eleitores. Para isso, todavia, é preciso compor uma ideia de práxis política que concretize o processo de catacrese configurado nestes discursos por meio do qual uma parte (os oprimidos), reivindica-se como todo (o povo), enquanto sujeito político capaz de autodeterminar-se.

Associado a um modo de governo voltado ao empoderamento político e econômico das maiorias, o populismo apresenta-se como ferramenta heurística útil para analisar não apenas a gênese, mas, também a performances dessas lideranças, uma vez no poder. Sob este prisma, o populismo no poder deve caminhar na implementação de mecanismos institucionais que empoderem a plebe ou a maioria intensa, criando canais que garantam sua participação direta nos processos decisórios, ou, no mínimo, estabeleçam dispositivos de controle e accountability. Caso contrário, ou ele se esgota como fenômeno discursivo, ou ele se transforma em tirania.

Isto porque, em contextos marcados pela presença de elites e instituições comprometidas em bloquear tal empoderamento, preservando a manutenção de um status quo que favoreça a situação de opressão das classes populares, provavelmente será necessário adotar um conjunto de medidas capazes de contornar estes obstáculos.

Esta preocupação atende ao meu questionamento inicial, referente à diferenciação de governos, movimentos e líderes que reivindicam ou são caracterizados a partir do 
conceito laclauniano de populismo, originalmente referido a performances discursivas. Esta limitação, embora reconheça os efeitos materiais do discurso ${ }^{5}$, visa ser superada mediante a incorporação de uma dimensão programática, que contempla políticas públicas e alterações institucionais implementadas pelos respectivos governos, utilizando como critério à própria ideia de empoderamento do povo que orienta a definição de Laclau. Diante disto, minha proposta foi operar um alargamento em sua formulação de modo a ampliar sua capacidade operacional, incorporando preocupações alheias à sua teorização, como, por exemplo aquelas apresentadas por Urbinatti.

Com este propósito, extrapolando a caracterização de Urbinati e Laclau, foi possível detectar, através da observação dos modos de ativação do conceito de populismo na América Latina alguns, elementos que contribuem para a gênese de movimentos populistas (a), mas, também para sua maior ou menor capacidade de implementar estas medidas (b).

Nesta medida, é interessante contar com um conjunto de variáveis que nos auxilie a entender e diferenciar modos de governo, utilizando o conceito de populismo como ferramenta metodológica que permita mensurar uma maior ou menor capacidade do líder de contornar limites políticos e institucionais, reduzindo os poderes de veto dos atores comprometidos em bloquear as decisões majoritárias. Estas variáveis podem ser organizadas em dois grupos:

a) Variáveis conjunturais:

Conjunturas recessivas deflagradas, por exemplo, pela adoção de medidas de austeridade, que, por sua vez, podem incluir:

i. Recomendações oriundas de instâncias exógenas (Troika6, no caso europeu; FMl e Banco Mundial, no caso latino-americano) que tendem a favorecer a configuração de um inimigo;

ii. Adoção de medidas que tornam mais visíveis os conflitos redistributivos, estimulando a polarização (povo x oligarquias/elites);

5 Sobre os efeitos materiais dos fenômenos discursivos, encontramos em HES uma definição interessante: "Os elementos linguísticos e não lingüísticos não são meramente justapostos, mas constituem um sistema de posições diferencial e estruturado - isto é, um discurso. Os aspectos diferenciais incluem, por conseguinte, uma dispersão de elementos materiais muito diversos" (LACLAU; MOUFFE, 1985, p. 108).

6 Termo utilizado para denominar a tríade formada pela Comissão Europeia, pelo Banco Central Europeu, pelo Fundo Monetário Internacional (FMI). 
iii.Cortes generalizados nos gastos governamentais, que tendem a aumentar o volume de demandas não atendidas, passíveis de serem agregadas a partir dos discursos populistas, em cadeias de equivalência.

b) Variáveis estruturais:

i) Políticas: Maior / menor concentração de poderes nas mãos do governo, seja ele de natureza parlamentarista ou presidencialista;

ii) Econômicas: Maior ou menor dispersão das atividades econômicas, bem como o papel desempenhado pelo Estado nesta dinâmica?

Como se pode observar estas variáveis, dizem respeito, por um lado, ao surgimento de cadeias de equivalência entre os cidadãos e, por conseguinte, ao surgimento de líderes populistas. Por outro lado, elas permitem mensurar a capacidade destas liderança de, uma vez no poder, agirem de modo a reduzir o número de atores e instituições com poder de bloquear transformações no status quo.

Sob esta perspectiva, como alerta Nadia Urbinati, o populismo é entendido como fenômeno que tem como consequência a desfiguração da democracia liberal, sendo, também, por ela causada. Esta é uma associação axiológica, porém não necessária, na medida em que existem elementos que aumentam ou diminuem a probabilidade de que estas lideranças, ultrapassem o plano discursivo e adotem uma práxis política propriamente populista. Tal correlação, contudo, não é estática. Daí a importância de conciliar variáveis estruturais e conjunturais que atuam sobre a capacidade dos atores e instituições de cada sistema (Legislativo, Judiciário, Partidos, Movimentos Sociais e Sindicatos, etc.) de atender às demandas da população e canalizar seus conflitos.

Na ausência destes sujeitos, a agenda política direcionada aos elos da cadeia de equivalência que une, pela privação, a imensa maioria dos cidadãos latino-americanos, utilizando a polarização e a formação de maiorias intensas para contornar obstáculos institucionais, pode ser uma opção racional e legítima. Essa agenda populista, todavia, precisa ir além da dimensão discursiva, enfatizada na conceitualização de Laclau,

7 Aqui me refiro a maior ou menor concentração da atividade econômica em determinada dinâmica produtiva. Esta variável é explorada na literatura que aborda o rentismo (LASERNA, 2006) sendo utilizada para se referir uma estrutura econômica dependente de uma única atividade, em particular, da exploração de recursos naturais, abordando suas consequências para a organização política, no tocante à centralização de poder na figura do chefe do Executivo. Em virtude das afinidades entre rentismo e populismo, exploradas em Silva (2015), sugiro a leitura de Gordon Tullock, Toward a Theory of the Rent seeking Society (1967) e Anne Krueger, The political economy of the rent seeking society (1974). 
avançando na direção de arranjos ulteriores aos princípios à democracia liberal, como alerta Urbinati.

Esse não é um movimento desprovido de perigos. Porém, talvez, esse seja um risco válido em contextos nos quais o arranjo tradicional não encontra as condições necessárias para seu funcionamento. Utilizar o arcabouço institucional que caracteriza a democracia liberal como parâmetro abstrato para condenar essas empreitadas é insistir em critérios normativos incompatíveis com a nossa realidade. Em face dela, um ideal de contra-hegemonia que permita mensurar os avanços na direção do empoderamento político e material do demos, me parece mais adequado. Para isso, é preciso incorporar esse componente normativo ao conceito de populismo, capacitando-o como ferramenta heurística capaz de analisar e hierarquizar fenômenos políticos (e políticas públicas) em termos de discurso e práxis.

\section{Referências}

ALVES, A. R. C. O conceito de hegemonia: de Gramsci a Laclau e Mouffe. Lua Nova, v. 80, p. 71-96, 2010.

ARDITI, B. Populism as an Internal Periphery of Democratic Politics. In: PANIZZA, F. (Ed.). Populism and the mirror of democracy. London: Verso, 2005. p. 73-104.

CARDOSO, F. H.; FALETTO, E. Dependencia y desarrollo en América Latina:ensayo de interpretación sociológica. México: Siglo Veintiuno, 1969.

COX, R. W. Gramsci, Hegemonia e Relações Internacionais: um ensaio sobre o método. Tradução de Dinah de Abreu Azevedo. Rio de Janeiro: Editora UFRJ, 2007. p. 101-123.

DORNBUSCH, R.; EDWARDS, S. The macroeconomics of populism. In: Dornbusch, R.; Edwards, S. The macroeconomics of populism in Latin America. Chicago: University of Chicago Press, 1991. p. 7-13.

FAUCHER, P.; DUCATENZEILER, G.; REA, J. C. Amerique Latine: Les echecs du liberal-populisme. Canadian Journal of Development Studies, v. 14, n. 2, p. 173-195, 1993. http://dx.doi.org/10 .1080/02255189.1993.9669512.

GERMANI, G.; IANNI, O.; DI TELLA, T. Populismo y contradicciones de clase en Latinoamerica. México: Ediciones Era, 1973.

GÓMEZ LEYTON, J. C.; MOREIRA, C.; RAUS, D. La nueva política en América Latina: rupturas y continuidades. Montevidéu: Flacso Uruguay, UNLa, Arcis, Trilce, 2008.

IANNI, O. La formación del Estado populista en América Latina. México: Ediciones Era, 1975. 
KAUFMAN, R.; STALLINGS, B. The political economy of Latin American populism. In: DORNBUSCH, R.; EDWARDS, S. The macroeconomics of populism in Latin America. Chicago: University of Chicago Press, 1991. p. 15-34.

LATORRE, C. In the name of the people: democratization, popular organizations, and populism in Venezuela, Bolivia, and Ecuador. European Review of Latin American and Caribbean Studies, n. 95, p. 27-48, 2013.

LACLAU, E. Minding the gap: the subject of politics. In: LACLAU, E. (Ed.). The making of the political identities. London: Verso, 1994. p. 1-40.

LACLAU, E. On populist reason. London: Verso, 2005. p. 87-88.

LACLAU, E. Puede haber Congresos con una voluntad antidemocrática: entrevista. [13 de junho, 2010]. Disponível em: <http://www.rebeldemule.org/foro/biblioteca/tema7954.html>. Acesso em: 15 jul. 2017.

LACLAU, E.; MOUFFE, C. Hegemony and socialist strategy: towards a radical democratic politics. Londres: Verso, 1985.

LANZARO, J. Gobiernos de izquierda en América Latina: entre el populismo y la social democracia: una tipología para avanzar en el análisis comparado. Análise de Conjuntura Observatório Político Sul-Americano, n. 12, dez, p. 1-20, 2007.

LASERNA, R. La trampa del rentismo. La Paz: Milenio, 2006.

MITRE, A. F. As peregrinações de um conceito: populismo na América Latina. Cadernos de História, v. 10, n. 13, p. 9-23, 2009.

O’DONNELL, G. Modernización y autoritarismo. Buenos Aires: Paidós, 1972.

PEREIRA DA SILVA, F. Da onda à era progressita: a hora do balanço. Revista Sures, v. 5, p. 67-94, 2015.

PEREIRA, L. C. B. Pactos políticos: do populismo à redemocratização. São Paulo: Brasiliense, 1985.

PEREIRA, L. C. B. Populismo econômico: ortodoxia, desenvolvimentismo e populismo na América Latina. São Paulo: Nobel, 1991a.

PEREIRA, L. C. B. A crise da América Latina: consenso de Washington ou crise fiscal. Pesquisa e Planejamento Economico, v. 21, n. 1, p. 3-23, 1991 b.

RODRIGUES, T.; SILVA, M. G. A razão populista de Ernesto Laclau: uma crítica agonística. Teoria e Cultura, v. 10, p. 173-195, 2015.

SACHS, J. Social conflict and populist policies in Latin America. Cambridge: National Bureau of Economic Research, 1989. (Working Paper, 2897).

SCHNEIDER, B. R. Brazil under Collor. World Policy Journal, v. 8, n. 2, p. 321-347, 1991.

SILVA, M. G. Entre César e o Demos: notas agonísticas sobre a democracia na Venezuela. Tese (Doutorado em Ciência Política)-Instituto de Estudos Sociais e Políticos, Universidade do Estado do Rio de Janeiro, Rio de Janeiro, 2013.

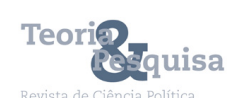


SILVA, M. G. Populismo, rentismo e Estado mágico: notas agonísticas sobre a democracia na Venezuela. Oikos, v. 13, p. 91-114, 2015.

SILVA, M. G. O Retorno do Mago: a democracia venezuelana entre a tradição e a ruptura. In: PERLATTO, F;; CHAVES, D. (Ed.). Repensar os populismos na América do Sul: debates, tradições e releituras. Macapa: Editora da Universidade Federal do Amapá, 2016. p. 265-285.

SMITH,W. Democracy, distributional conflicts and macroeconomic policymaking in Argentina, 1983- 89. Journal of Interamerican Studies and World Affairs, v. 32, n. 2, p. 1-42, 1990.

SMITH, W. State, market and neoliberalism in post-transition Argentina. Journal of Interamerican Studies and World Affairs, v. 33, n. 4, p. 45-82, 1991. http://dx.doi.org/10.2307/165879.

STEIN, S. Populism in Peru. Madison: University of Wisconsin Press, 1980.

URBINATI, N. Democracy disfigured: opinion, truth, and the people. Cambridge: Harvard University Press, 2014. p. 45-46.

VILAS, C. La democratización fundamental: el populismo en América Latina. México: Consejo Nacional para la Cultura y las Artes, 1994.

VILAS, C. Populismos reciclados o neoliberalismo a secas? El mito del "neopopulismo" latinoamericano. Revista de Sociologia e Politica, v. 22, p. 27-51, 2004.

WEFFORT, F. Classes populares e desenvolvimento social: contribuição ao estudo do populismo. Santiago: ILPES, 1968.

WEYLAND, K. Neopopulism and neoliberalism in Latin America: unexpected affinities. Studies in Comparative International Development, v. 31, n. 3, p. 3-31, 1996. http://dx.doi.org/10.1007/ BF02738987.

WEYLAND, K. Clarifying a contested concept: populism in the study of Latin American politics. Comparative Politics, v. 34, n. 1, p. 1-22, 2001. http://dx.doi.org/10.2307/422412.

Recebido: 04 fev., 2017

Aceito: 21 abr., 2017 